\title{
A Preliminary Exploration of Heavy Metal Contamination within Aviccenia marina in the United Arab Emirates
}

Mariam Al Hosani ${ }^{1}$ and Fatme Al Anouti ${ }^{2 *}$

${ }^{1}$ Industrial Hygienist, Abu Dhabi Gas Industries Ltd., Abu Dhabi, UAE

${ }^{2}$ Assistant Professor, Zayed University, Natural Science and Public Health Department, UAE

\begin{abstract}
Mangrove forests within the United Arab Emirates are being heavily exposed to anthropogenic contaminants due to pollution and urbanization. However, there is very limited research pertaining to this subject and the extent to which such mangroves can take up and store heavy metals is still unclear. In this research study, the concentrations of zinc, copper, lead and chromium in the grey mangrove Avicennia marina were measured. Samples were taken from five different sites within the capital city and tested using Flame Atomic Absorption Spectrophotometer (FAAS) for the presence of heavy metals. The total concentrations of selected heavy metals in the mangrove leaves were compared to the general heavy metal concentration for plant. The general heavy metal concentration for plant was based on the heavy metals concentrations measured in the mature leaf tissue of various plant species. The comparison showed that the total concentrations did not exceed the general concentration. Nevertheless, the fact that the leaves which are the least bioaccumulative part of the mangrove warrants further investigation over a longer period of time and sampling from roots and sediments to determine whether heavy metal contamination within the mangrove ecosystem is a possibility.
\end{abstract}

Keywords: Heavy metal contamination; Aviccenia marina; Mangrove; Anthropogenic

\section{Introduction}

A rising level of heavy metals has been reported in mangrove sediment biotas globally. This could be indicative of the high level of polluting activities caused by human influence through anthropogenic contaminants [1-8]. As heavy metals cannot be biologically degraded, they get transferred and eventually concentrated into mangrove tissues from sediments, posing a threat to this plant and other organisms within the same ecosystem through food chain interaction $[9,10]$. Mangroves play a crucial role in maintaining a dynamic ecological balance in coastal and marine environments [1-8]. For instance, a mangrove habitat provides breeding and nursery grounds for many aquatic species and contributes to the stabilization of adjacent coastal landforms against cyclones and tidal waves [2]. Worldwide, there are 59 different mangrove species with one only Avicennia marina; grey mangrove; being endemic to the United Arab Emirates (UAE) [3]. This cosmopolitan species which grows through many coastal areas, such as Eastern Africa, the Arabian Gulf, and Indo-Melanesia is characterized by its tolerance to extreme and harsh environmental conditions [3,5]. Numerous studies have demonstrated a greater tolerance by Avicennia marina to various metals when compared with other mangrove species. This quality has enabled researchers to utilize particularly this mangrove species as a bio-indicator of heavy metal pollution to obtain quantitative information regarding the quality of its environment $[4,10]$. Nevertheless, not enough research investigations have been conducted in the UAE, thus emphasizing the need for more research in this area.

The heavy metals which have been typically associated with the pollution of mangrove forests and swamps are lead, zinc, copper, mercury, nickel, chromium, cadmium, manganese and magnesium $[1,11,12]$. Some are essential plant nutrients, such as manganese and zinc, and are found to be more abundant than the other metals due to high natural background levels. Others, like nickel and mercury, are non-essential and are therefore considered as pollutants [1]. However, elevated concentrations of essential and non-essential heavy metals, collectively, indicate a negative human input in the mangrove environment. One study revealed high lead levels in the mangrove sediments of Abu Dhabi, the capital of the UAE [3]. This was attributed to the massive urbanization developmental projects which have detrimental impacts in terms of solid wastes, oil spills, and the high rate of gas combustion. Interestingly, not many studies monitor the same combination of heavy metals within mangrove ecosystems, though the two metals that are almost always monitored by investigators are zinc and lead [1-3].

Mangrove sediments often act as natural sinks for heavy metals as they have a high capacity to preserve heavy metals from freshwater rivers, tidal waters, and storm water runoff [13]. Other fauna and flora in the mangrove environment do not possess the mechanisms used by mangrove plants to regulate the uptake of heavy metals. Therefore, heavy metal levels that are too low to induce a negative effect on mangroves may be just sufficient to harm another species. Lead, at excessive levels, could cause death to many organisms and it could be extremely toxic at even low levels. Cadmium is another substance that poses a threat to animal species, as ingesting trace quantities of it can jeopardize the organism's physiology, health, reproduction and survival [11]. Some researchers have experimented with acute exposure to chromium on fish. Their research focused on chromium in particular as it can readily cross-cellular membranes in aqueous solutions, making this heavy metal one of the most dangerous on aquatic fauna [14]. Acute exposure to chromium had been shown to cause degenerative changes in the histology of kidney, liver and gills tissues; the kidney's renal tubules were atrophied, the liver hepatocytes experienced a degenerative

*Corresponding author: Fatme Al Anouti, Assistant Professor, Zayed University, Natural Science and Public Health Department, Abu Dhabi, UAE, Tel: 971-503-019-807; E-mail: Fatme.AlAnouti@zu.ac.ae

Received February 17, 2014; Accepted May 22, 2014; Published May 25, 2014

Citation: Al Hosani M, Al Anouti F (2014) A Preliminary Exploration of Heavy Metal Contamination within Aviccenia marina in the United Arab Emirates. J Environ Anal Toxicol 4: 232. doi: 10.4172/2161-0525.1000232

Copyright: (c) 2014 Al Hosani M, et al. This is an open-access article distributed under the terms of the Creative Commons Attribution License, which permits unrestricted use, distribution, and reproduction in any medium, provided the original author and source are credited. 
necrotic condition, and the gills were severely injured [14].

Mangrove areas in the UAE along with other coastal habitats have been recently subjected to recreational development, industrial installations, and urbanization in general. Studies that have been carried out previously in the UAE have revealed that there are many discarded materials disposed around mangroves [3]. These materials include automobiles, batteries, transformers and tires. Wastewater and oil spills have also been among the anthropogenic inputs that mangroves have been subjected to. The imminent consequence of these activities is the accumulation of heavy metals in sediments and within plant tissue. This could in turn lead to bioaccumulation effects along the food chain [3]. The aim of this study is to conduct a preliminary investigation of contamination in mangrove ecosystems within Abu Dhabi by measuring the level of four different heavy metals (zinc, copper, lead and chromium) in the leaves of representative mangrove habitats of Abu Dhabi leaves from five different sites.

\section{Methodology}

\section{Study sites and sampling methodology}

The study sites were the mangrove areas in five different locations within Abu Dhabi: the Musaffah channel, Eastern corniche, Saadiyat Island, Al Samaliyyah Island, and Yas Island (Figure 1). The mangroves on Saadiyat Island were used as a control because the habitat is protected to some extent with minimal level of urbanization, while the other areas-namely, Al Samaliyyah and Musaffah channel-are predicted be contaminated due to the abundance of developmental projects. Among all five selected sites, Al Samaliyyah Island has been subjected to intensive anthropogenic inputs (i.e. construction work) for the longest time, while Musaffah is considered the industrial hub of Abu Dhabi city, and therefore rich with chemical residues [6]. From each of the five sites, a sample of 16 leaves was obtained from three randomly selected mangrove plants located within 5 meters of the coastline. These plants were all of good health and measured 2 to 3 meters in height.

\section{Heavy metal analysis by Flame Atomic Absorption Spectroscopy}

Extraction: Mangrove leaves were collected (within a one week period in April 2011), wrapped with aluminum foil and kept at $4^{\circ} \mathrm{C}$ until transported to the laboratory. The sample preparation procedure was adapted from the methods described by Nazli and Hashim [15]:

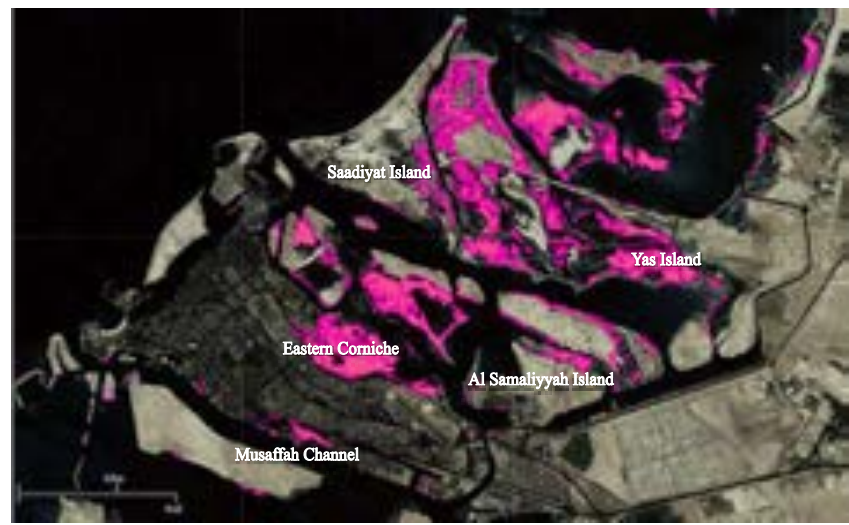

Figure 1: Mangrove Distribution in Abu Dhabi (source: coastalatlas.ead.ae) the leaf samples were washed with distilled water to remove surface contaminants before being placed in an oven at $157^{\circ} \mathrm{C}$ to dry overnight. Meanwhile, $100 \mathrm{ml}$ of concentrated $\mathrm{HNO}_{3}, 300 \mathrm{ml}$ of $\mathrm{HCL}$ and 600 $\mathrm{ml}$ of distilled water were combined in a volumetric flask to produce a nitric acid-hydrochloric acid dilute at 1:3 ratios. When they have sufficiently dried, the leaves were removed from the oven and grinded to fine particles using a pestle and mortar. The electronic balance was used to weigh 0.1 grams of the grinded leaf sample to be digested in 10 $\mathrm{ml}$ of the nitric acid-hydrochloric acid dilute in a $50 \mathrm{ml}$ beaker over a hotplate. A thermometer was used to ensure the solution and leaf mixture has reached a temperature of $80^{\circ} \mathrm{C}$. The digested solution was filtered through a Whatman filter paper on a Buchner funnel that was fixed above a side arm flask. Vacuum tubing was attached to the side arm flask and a running water tap to create a vacuum that would enhance the filtration of the digested solution. Using a pipette, the filtrate was transported to a volumetric flask and completed to $100 \mathrm{ml}$ with distilled water. The sample solution was stored in a fridge (maintained at a temperature of $4^{\circ} \mathrm{C}$ ) until it underwent the heavy metal analysis through air/acetylene Flame Atomic Absorption Spectrophotometer (Agilent Technologies). Three sample solutions were produced from each mangrove leaf sample.

\section{Heavy metal analysis}

Metal analysis was carried out on the resultant digests using FAAS, with the use of prepared standards (run before each batch) to determine sample concentrations. To ensure precision of FAAS results, three replicates of each sample were run to ensure measured absorbencies were consistent. Standard solutions were prepared for each of the four heavy metals by dissolving the salts of these metals in distilled water [15]. For Zinc, the solutions contained $0.5 \mathrm{ppm}, 1 \mathrm{ppm}$, and $1.5 \mathrm{ppm}$. Solutions of $2 \mathrm{ppm}, 5 \mathrm{ppm}$, and $20 \mathrm{ppm}$ were prepared from lead. The Copper solutions were of $2 \mathrm{ppm}, 4 \mathrm{ppm}$, and $6 \mathrm{ppm}$, while those of Chromium contained $2 \mathrm{ppm}, 5 \mathrm{ppm}$, and $10 \mathrm{ppm}$. This was done to create a calibration curve that provides a correlation between the concentration of the chemical and the rate at which the atoms are absorbed [15]. This in turn helps in producing an accurate measurement of the heavy metal content in the sample solutions. In order to carry out heavy metal analysis, the suction tube extending from the FASS was first inserted into a blank solution consisting of $1 \mathrm{ml} \mathrm{HCl}$ and $99 \mathrm{ml}$ distilled water. The tube was then inserted in the three standard solutions of a heavy metal to create a calibration curve before being inserted in the sample solution. The heavy metal content was recorded on the machine software. The measurement $\mu \mathrm{g} / \mathrm{g}$ was in microgram (of heavy metal) per gram (of mangrove leaf tissue).

\section{Results and Discussion}

The concentrations of the four heavy metals in the five different selected sites are shown in Table 1. The highest concentration value observed was that of zinc at $3.873 \mu \mathrm{g} / \mathrm{g}$ in Saadiyat Island. This value was followed closely also by zinc in Yas island $(3.857 \mu \mathrm{g} / \mathrm{g})$ and in Eastern Corniche $(3.181 \mu \mathrm{g} / \mathrm{g})$. Zinc concentrations within mangrove leaves in Musaffah and Al Samaliyyah were significantly lower. The concentrations of the other metals were all below 0.12 , and were, therefore displayed in a bar graph separate from the one displaying zinc. Lead concentrations are shown to be significantly higher than those of copper and chromium in Yas, Saadiyat, and Eastern corniche. The mangrove leaves in Musaffah channel and Al Samaliyyah contained lower trace metal levels than the rest of the sites. Copper was most abundant in the Eastern corniche $(0.023 \mu \mathrm{g} / \mathrm{g})$, while chromium existed in the highest concentrations in Al Samaliyyah island (0.019 


\begin{tabular}{|l|c|c|c|c|}
\hline Site & Copper & Lead & Chromium & Zinc \\
\hline Yas & $0.009 \pm 0.003$ & $0.099 \pm 0.014$ & $0.015 \pm 0.003$ & $3.857 \pm 0.216$ \\
\hline Musaffah Channel & $0.005 \pm 0.001$ & $0.020 \pm 0.006$ & $0.013 \pm 0.002$ & $0.111 \pm 0.005$ \\
\hline Al Samaliyyah & $0.005 \pm 0.002$ & $0.010 \pm 0.002$ & $0.019 \pm 0.005$ & $1.293 \pm 0.078$ \\
\hline Eastern Corniche & $0.023 \pm 0.007$ & $0.090 \pm 0.003$ & $0.005 \pm 0.001$ & $3.181 \pm 0.192$ \\
\hline Saadiyat & $0.005 \pm 0.002$ & $0.108 \pm 0.013$ & $0.004 \pm 0.0008$ & $3.873 \pm 0.232$ \\
\hline $\begin{array}{l}\text { Average Concentration } 0.0094 \pm 0.00770 .0654 \pm 0.0455 \\
2.463 \pm 1.684\end{array}$ \\
\hline
\end{tabular}

Mean values \pm standard deviation $(n=3)$

Table 1: Heavy metal concentrations ( $\mu \mathrm{g} / \mathrm{g}$ dry weight) in mangrove leaves.

$\mu \mathrm{g} / \mathrm{g})$. Although a higher level of all tested heavy metals was expected for Al Samaliyyah and Musaffah channel due to the abundance of developmental projects, the results indicated the opposite. The high zinc concentrations could be attributed to high natural background levels in the selected sites. More leaf samples should therefore be collected to confirm any conclusions. Moreover, variations within sites may be attributed to effects of biological and physical phenomena, such as salinity changes, wind and waves which could lead to bioturbation, re-suspension and erosion that are known to affect the metal concentrations in surface sediments $[1,16]$. The mean concentrations for each of the heavy metals across all selected sites were also recorded in Table 1. Zinc is shown to be the most abundant metal $(2.463 \mu \mathrm{g} / \mathrm{g})$, while lead ranks as the second most abundant heavy metal on average. It is observed that the mean lead level is almost 6 folds higher than the mean concentrations of copper and chromium.

However, the mangrove leaves from all sites contain zinc in a much higher concentration than all the other metals, with a maximum concentration of $3.88 \mu \mathrm{g} / \mathrm{g}$. This is in concordance with other studies which demonstrated that zinc is a highly mobile metal which could accumulate in plant leaves in great quantities $[4,15]$. The concentrations of lead are the second highest, and are followed by chromium then copper. The fact that the leaves of Avicennia marina, being the least bioaccumulative part of the plant, reflected the presence of heavy metals, could mean that higher concentrations are present in the roots and the surrounding sediments $[16,17]$. Further investigation into the presence of heavy metals in mangrove roots and sediments is hence needed before conclusions are to be made. The total concentrations of selected heavy metals in the mangrove leaves were compared to the general heavy metal concentration for plants. The general heavy metal concentration for plant was based on the heavy metals concentrations measured in the mature leaf tissue of various plant species. The comparison showed that the total concentrations did not exceed the general concentration, which ranged from 20 to $400 \mu \mathrm{g} / \mathrm{g}$ for the metals of concern [18].

The concentrations of various metals in the plant tissue differ from one part of the plant to another. Mangrove roots appear to have similar metal concentrations to the sediments, while mangrove leaves have significantly less accumulated trace metals in their tissue [10]. It is believed that certain species are able to actively avoid the uptake of metals, regardless of how high the metal concentrations are in the sediments. Exclusion of ions, cell wall immobilization, and barriers at root epidermis are some of the plant tolerance mechanisms used against heavy metals. It has been reported that very low heavy metal concentrations accumulated in leaf tissues because most absorbed heavy metals accumulated in stem and root tissue [10]. So far, root tissue has been recognized as the most accurate part of the mangrove to use as a bio-indicator for heavy metal pollution. Studies carried out in unpolluted areas in Australia have showed that mangrove leaves have very little, almost insignificant, amounts of non-essential heavy metals [10]. In India, Panama, and Hong Kong, mangrove forests are placed near areas under intense development and industrialization; thus, heavy metal concentrations have been reported to be several folds higher than they are in Australia $[1,10]$.

Moreover, the availability of heavy metals in mangrove sediments to plants is influenced by sediment characteristics such as $\mathrm{pH}$, cation exchange, redox conditions and chlorine content. Further study is needed to investigate these characteristics in order to demonstrate whether contamination of sediments with heavy metals in fact has occurred. A research study has revealed high lead levels in the grey mangrove sediments of the United Arab Emirates most likely as a result of massive expansion of developmental construction projects. The vast developmental growth with emphasis on recreational reshaping of coastal beaches has subjected mangroves to discarded contaminants which could have lead to the sedimentation of heavy metals within plant tissue [3]. Research investigations of the status of heavy metal pollution in grey mangrove habitat biota within the Red Sea coastal areas of Saudi Arabia have also documented a very high concentration particularly for copper and chromium [17]. Similarly in India and Hong Kong, the intense development and industrialization have posed an ecological threat to the nearby mangrove forests which have revealed elevated levels of heavy metals that exceed sediment quality guidelines particularly with lead $[1,11,12]$. It has been predicted that the levels of lead within mangrove sediments in the Gulf region and others could be increasing in the coming few years due to impacts of oil spills and the higher rate of fuel consumption $[3,7,8]$.

In conclusion, the health of mangrove habitats has the potential to become jeopardized by heavy metal contamination; therefore mitigation efforts must be made to prevent the issue from escalating. This preliminary study provides implications in terms of directing environmental protection and mitigation efforts to the areas where they are most needed. Future studies are needed to provide a better and more comprehensive investigation of heavy metal mobility, bioaccumulation and ecotoxicology within the indicator mangrove species by collecting more samples and profiling for different metals within the mangrove plants and sediments over a long period of time. Temporal accumulation relationships could provide valuable insights into the conservation of mangrove ecosystem within the UAE.

\section{References}

1. Lewis $M$, Pryor R, Wilking $L$ (2011) Fate and effects of anthropogenic chemicals in mangrove ecosystems: a review. Environ Pollut 159: 2328-2346.

2. Zhou YW, Zhao B, Peng YS, Chen GZ (2010) Influence of mangrove reforestation on heavy metal accumulation and speciation in intertidal sediments. Mar Pollut Bull 60: 1319-1324.

3. Shriadah MA (1999) Heavy metals in mangrove sediments of the United Arab Emirates shoreline. Water, Air and Soil Pollution 116: 523-534.

4. MacFarlane GR, Pulkownik A, Burchett MD (2003) Accumulation and distribution of heavy metals in the grey mangrove, Avicennia marina (Forsk.) Vierh.: biological indication potential. Environmental Pollution 123: 139-151.

5. Saravanakumar A, Serebiah JS, Sun J, Thivakaran GA, Rajkumar M (2009) Forest structure of arid zone mangroves in relation to their physical and chemical environment in the western Gulf of Kachch,, Gujarat, Northwest coast of India. Journal of Coastal Conservation 13: 217-234.

6. Das M (2011). Personal Communication.

7. Baillif $P$, Baltzer F, Cossa D, Lallier-Verges E, Marchand C, Alberic P (2006) Heavy metals distribution in mangrove sediments along the mobile coastline of French Guiana. Marine Chemistry 98: 1-17.

8. Brix KV, DeForest DK, Adams WJ (2007) Assessing metal bioaccumulation 
Citation: Al Hosani M, Al Anouti F (2014)A Preliminary Exploration of Heavy Metal Contamination within Aviccenia marina in the United Arab Emirates. J Environ Anal Toxicol 4: 232. doi: 10.4172/2161-0525.1000232

Page 4 of 4

in aquatic environments: The inverse relationship between bioaccumulation factors, trophic transfer, factors and exposure concentration. Aquatic Toxicology 84: 236-246.

9. Creighton N, Twining J (2010) Bioaccumulation from food and water of cadmium, selenium and zinc in an estuarine fish, Ambassis jacksoniensis. Mar Pollut Bull 60: 1815-1821.

10. Defew LH, Mair JM, Guzman HM (2005) An assessment of metal contamination in mangrove sediments and leaves from Punta Mala Bay, Pacific Panama. Mar Pollut Bull 50: 547-552.

11. Agoramoorthy G1, Chen FA, Hsu MJ (2008) Threat of heavy metal pollution in halophytic and mangrove plants of Tamil Nadu, India. Environ Pollut 155: 320-326.

12. Kakudidi E, Mutumba G, Oryem Origa H, Sekabira K, Basamba, TA. (2010). Assessment of heavy metal pollution in the urban stream sediments and its tributaries. International Journal of Environmental Science and Technology 7: $435-446$

13. Wong YS, Tam NFY (1999) Mangrove soils in removing pollutants from municipal wastewater of different salinities. Journal of Environmental Quality 28: $556-565$

14. Mishra AK, Mohanty B (2008) Acute toxicity impacts of hexavalent chromium on behavior and histopathology of gill, kidney and liver of the freshwater fish, Channa punctatus (Bloch). Environ Toxicol Pharmacol 26: 136-141.

15. Nazli MF, Hashim NR. (2010) Heavy metal concentrations in an importan mangrove species, Sonneratia caseolaris, in Peninsular Malaysia. Environment Asia 3: 50-55.

16. Sarika PR, Chandramohanakumar N (2008) Geochemistry of heavy metals in the surficial sediments of mangroves of the south west coast of India. Chemistry and Ecology 24: 437-447.

17. Usman AR, Alkredaa RS, Al-Wabel MI (2013) Heavy metal contamination in sediments and mangroves from the coast of Red Sea: Avicennia marina as potential metal bioaccumulator. Ecotoxicol Environ Saf 97: 263-270.

18. Alloway BJ (1990) Heavy metals in soils. John Wiley and Sons, Inc, New York. 